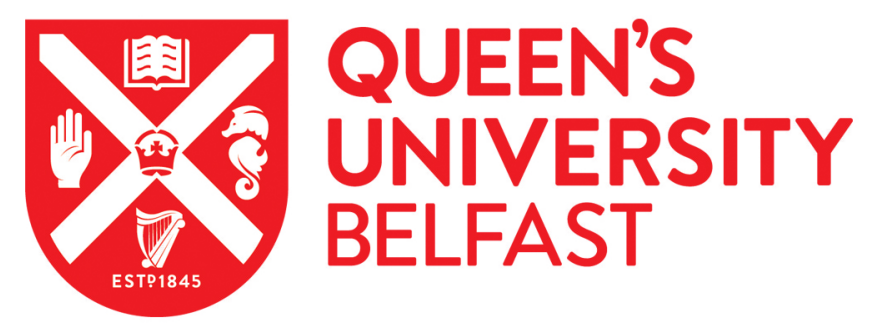

\title{
Indigenous rights in Chile: National identity and majority group support for multicultural policies
}

Pehrson, S., Gonzalez, R., \& Brown, R. (2011). Indigenous rights in Chile: National identity and majority group support for multicultural policies. Political Psychology, 32(4), 667-690. https://doi.org/10.1111/j.14679221.2011.00827.x

Published in:

Political Psychology

Document Version:

Early version, also known as pre-print

Queen's University Belfast - Research Portal:

Link to publication record in Queen's University Belfast Research Portal

\section{General rights}

Copyright for the publications made accessible via the Queen's University Belfast Research Portal is retained by the author(s) and / or other copyright owners and it is a condition of accessing these publications that users recognise and abide by the legal requirements associated with these rights.

Take down policy

The Research Portal is Queen's institutional repository that provides access to Queen's research output. Every effort has been made to ensure that content in the Research Portal does not infringe any person's rights, or applicable UK laws. If you discover content in the Research Portal that you believe breaches copyright or violates any law, please contact openaccess@qub.ac.uk. 
INDIGENOUS RIGHTS IN CHILE

- 1 -

INDIGENOUS RIGHTS IN CHILE: NATIONAL IDENTITY AND MAJORITY

GROUP SUPPORT FOR MULTICULTURAL POLICIES

\author{
Samuel Pehrson \\ (Queen’s University Belfast, Northern Ireland) \\ Roberto González \\ (Pontificia Universidad Católica de Chile) \\ Rupert Brown \\ (University of Sussex, United Kingdom)
}

This is an author-produced, peer-reviewed version of the following article:

Pehrson, S., Gonzalez, R. \& Brown, R. (2011). Indigenous rights in Chile: National identity and majority group support for multicultural policies. Political Psychology, 34, 667-690.

Published in final form at:

http://onlinelibrary.wiley.com/doi/10.1111/j.1467-9221.2011.00827.x/abstract 


\section{INDIGENOUS RIGHTS IN CHILE}

\section{ABSTRACT}

We examine support for policies affecting indigenous ethnic minorities in Chile.

Specifically, we examine the role of national group definitions that include the largest indigenous group - the Mapuche - in different ways. Based on questionnaire data from non-indigenous Chilean students $(\mathrm{N}=338)$, we distinguish empirically between iconic inclusion, whereby the Mapuche are seen as an important part of Chile's history and identity, on the one hand, and egalitarian inclusion, which represents the Mapuche as citizens of equal importance to the non-indigenous majority, on the other. Both forms of inclusion positively predict support for indigenous rights, independently of participants' political affiliation, strength of national identification and social distance. A second study $(\mathrm{N}=277)$ replicates this finding whilst controlling for right-wing authoritarianism, social dominance orientation, blind patriotism and constructive patriotism. It also finds iconic inclusion to be predictive of a proMapuche position regarding the unrest over the issue of ancestral land in 2009. We conclude that understanding how national identity affects attitudes about minority rights necessitates appreciating the importance of particular meanings of nationality, and not only the strength of identification. 


\section{INDIGENOUS RIGHTS IN CHILE}

- 3 -

Nation-states entail a 'societal culture', which consists of principles and assumptions on which governance and laws can be based, symbols through which the abstraction of the nation is represented, and often a primary language through which state institutions and bureaucracies operate (Kymlicka, 2001). They are not 'cultureneutral' because the ideology of nationalism underlying them assumes that shared culture of some sort is necessary for political community.

However, the populations of nation states are very often made up of several groups that assume themselves to have different origins from one another, and to have different cultures, which is to say that they relate to each other in terms of ethnicity. ${ }^{1}$ These various ethnic groups do not typically have equal influence over what happens in the country, and we can speak of majority and minority ethnic groups in terms of numerical size, as well as in terms of power. A potential consequence of this is that the process of nation-building may disadvantage minority ethnic groups because it will typically be determined by majority, and therefore largely reflect their own practices and values. Similarly, the official histories disseminated through schools and so forth might exclusively reflect the perspective of the majority group members who write them, whilst devaluing or ignoring the perspectives of less powerful groups. Languages in which education and administration are conducted are more likely to be the first language for majority ethnic groups than for minority ones. All of this has potentially harmful implications for minority group members' opportunities for education, employment and political participation, not to mention their dignity. The domination of national culture by the majority means that minorities can be seen as backward or deviant, and imply that they are less worthy of respect. Cultural

\footnotetext{
${ }^{1}$ Of course, the same population almost certainly understand themselves in terms of other collective identities as well. The point here is that ethnicity is a property of a particular social relationship, rather than an inherent feature of either individuals or groups.
} 


\section{INDIGENOUS RIGHTS IN CHILE}

-4 -

domination can be experienced as a form of discrimination (Merino, Mellor, Saiz, \& Quilaqueo, 2009).

Rather than put up with this, minority groups may mobilize around a collective identity to resist the expectation that they should conform to a national culture that is dictated by others, or see their difference portrayed as inferior or abnormal. Such mobilizations often advance demands for official recognition and respect, and sometimes a certain degree of political autonomy. Terms such as 'the politics of recognition' and 'multiculturalism' have been used to describe these demands for minority rights (Taylor, 1992; Verkuyten, 2006). The politics of recognition is relevant to various types of minority groups, including sexual minorities, immigrants, and, in states formed through settler-colonialism, indigenous ethnic groups (Kymlicka, 2002). It is this latter case that concerns us here.

Political scientists, sociologists and psychologists have produced a considerable literature on processes of mobilization that are relevant to understanding the politics of recognition (Polletta \& Jasper, 2001; van Zomeren, Postmes \& Spears, 2008). However, our focus is not on the mobilization and collective action for indigenous rights itself, but rather the issue of how a non-indigenous majority might react to such minority demands. Social change entails not only mobilization around a minority identity, but also contestation over the meaning of a shared category in such as way as to engage the solidarity of the majority (Subašić, Reynolds \& Turner, 2008). Because the majority's domination of national culture is at stake (Kymlicka, 2001), it is necessary to consider understandings of nationhood when attempting to understand attitudes about indigenous rights. Therefore, we ask how non-indigenous people's support for policies that address indigenous rights might be affected by how they define their national identity and their level of attachment to it. 


\section{INDIGENOUS RIGHTS IN CHILE}

- 5 -

\section{National identity and intergroup relations}

The notion of 'social identity' links psychological and social phenomena. It does this by conceptualising the self-concept in such a way that people are understood to represent themselves in terms of group memberships, and not only in terms of their individuality (Tajfel, 1978a; Tajfel \& Turner, 1979; Turner, Hogg, Oakes, Reicher, \& Wetherell, 1987; Turner, 1999). Thus, one's conception of who and what one is derives from how one is positioned within a social structure, how one represents social groups that one does and does not belong to, the relationships between such groups, and so forth. Furthermore, social identity not only derives from how people make sense of their social world, but can also act as a source of social change: it affects possibilities for solidarity with others, as well the appraisal of others as problematic for one's prestige, status or interests (Reicher, 2004; Subašić et al., 2008; Tajfel \& Turner, 1979). It is therefore a valuable construct in accounting for the relations between psychological and political processes. Indeed, work stemming from the social identity tradition has provided insights (and stimulated lively debates) on a broad range of politically relevant processes. These include social movements and collective action (Drury \& Reicher, 2005; Simon \& Klandermans, 2001); inter-party relations in political coalitions (González et al., 2008); processing and evaluation of persuasive information (Hogg \& Smith, 2007); leadership (Haslam \& Platow, 2001); and collective guilt and reparations following group-based injustices (Brown, González, Zagefka, Manzi, \& Čehajić, 2008; Wohl, Branscombe, \& Klar, 2006). The social identity perspective has also been applied in a number of ways to the topic of minority rights, examining, for example, the effects of group status and identification on support for multiculturalism (for a review, see Verkuyten, 2006). Indeed, the rise 


\section{INDIGENOUS RIGHTS IN CHILE}

-6 -

of mobilizations around minority identities was part of the original impetus for the theory (Tajfel 1978b; Tajfel \& Turner, 1979).

In its emphasis on generic processes, the social identity approach has tended not to examine the specific content and meanings of collective identities such as nationality (Billig, 1995; Huddy, 2001; Reicher \& Hopkins, 2001b) and gender (Cameron \& Lalonde, 2001), and has generally overlooked the fact that social categories pertain to historically situated ideological traditions (Reicher \& Hopkins, 2001a). This, together with the common misperception that social identity theory posits a ubiquitous tendency for ethnocentrism (Reicher, 2004; Turner, 1999), has undermined the explanatory potential of the theory, as well as the antireductionist project that it was originally grounded in (Tajfel, 1972, 1981).

However, some social identity researchers have sought to restore the balance between an appreciation of the meanings of specific collective identities and general identity processes. Reicher and Hopkins (2001b), for example, present evidence that national categories can be rhetorically constructed in multiple ways, and that these constructions orient collective action differently. By analysing the politicians' conversations about Scotland and Scottish independence, they show that national identity can be employed to argue either for or against independence, depending on how 'Scottishness' is constructed. The importance of identity content has also been highlighted using more traditional quantitative methods. Survey research conducted in Northern Ireland, for example, finds that the strength of identification as either Protestant or Catholic is related to negative orientations towards the other group only among those who construe being a Catholic or Protestant as entailing an antagonistic relationship with the other group (Livingstone \& Haslam, 2008). Thus, the consequences of collective identification are contingent on the meanings associated 


\section{INDIGENOUS RIGHTS IN CHILE}

- 7 -

with particular identities. The relationship between ingroup identification and outgroup attitudes cannot be reduced to generic processes within individual minds.

As we have said, the current study is concerned specifically with national identity and majority group support for minority rights. One aspect of national identity content that has been shown to be consequential for intergroup relations is the demarcation of group boundaries. National groups can be defined in different ways, determining who is included and who is excluded from them. One study, for example, finds causal effects of the extent to which English adolescents endorse an 'ethnic' definition of their national group (based on ancestry, thus designating immigrants as immutably foreign) on hostile intentions towards asylum seekers (Pehrson, Brown, \& Zagefka, 2009). Ethnic and civic national definitions also relate to variation in the relationship between national identification and anti-immigrant prejudice within and between national contexts (Pehrson, Vignoles, \& Brown, 2009; Pehrson \& Green, in press). Therefore, the inclusivity of national boundary definitions, which varies within and between national groups, is all-important.

What might this evidence imply for indigenous rights? If national ingroup definitions matter in host-immigrant relations, then one can reasonably expect them to matter in relations between indigenous and non-indigenous people as well. Thus, if we are to examine associations between national identity and support for indigenous rights, then we need to consider the way in which the national group is defined, including the extent and manner in which indigenous people are included within the national group definition, and not only the strength of identification. 


\section{INDIGENOUS RIGHTS IN CHILE}

-8 -

Iconic versus egalitarian inclusion

As we have explained, work on national definitions in relation to antiimmigrant prejudice has drawn on the distinction between ethnic and civic forms of national group boundary demarcation, with the ethnic form constituting a relatively exclusionary definition in comparison to the civic form. In a similar way, nonindigenous people may represent indigenous minorities as belonging to a greater or lesser degree to their national community. However, the case of indigenous minorities is not identical to that of immigrant groups, and potentially allows for more ambivalence in how the national boundary is construed. Rather than national definitions either including indigenous people or not (as a straightforward application of the civic-ethnic dichotomy would imply), there may be different kinds of inclusion and exclusion from the representation of the national group.

We propose a distinction between iconic inclusion and egalitarian inclusion, and suggest that this is relevant to understanding the national definitions in countries where there is an indigenous minority. Iconic inclusion involves representations of the nation in which the indigenous group plays a central and defining role. For example, historic members of the indigenous groups may be prominent national heroes, and the content of national symbols and iconography may refer to the role of the indigenous people in the formation of the nation. In this way, they are not represented as alien to the national group, but rather are given a central role in defining it. Iconic inclusion might be contrasted with what we shall call 'egalitarian inclusion', which is a representation of both indigenous and non-indigenous people belonging to the same national group as equal citizens. It therefore emphasises equality between groups, and common membership to the 'nation', understood as the basis of collective solidarity (Greenfeld, 1996). We suggest that both of these forms of inclusion lead to an 


\section{INDIGENOUS RIGHTS IN CHILE}

- 9 -

increased willingness on the part of the non-indigenous majority to be supportive of minority rights.

It must be emphasised that the constructs of inclusion that we suggest refer to the inclusion of indigenous people within the definition of the national category; it is about how non-indigenous Chileans represent their national group. This is not the same as the extent to which people are actually included in a structural, political or economic sense. Evaluating the later would entail different kinds of indicators, such as the extent of indigenous employment, educational opportunity, participation in electoral politics, and so on.

\section{The Mapuche in Chile}

Chile is home to a number of indigenous groups, which together represent approximately 7.5 percent of the population (Gacitúa-Marió, 2000). The largest of these is the Mapuche. Representations of the Mapuche have a long history of being incorporated into constructions of Chilean nationhood. Much of this involves the image of the Mapuche as warriors who resisted Spanish invasions for over 300 years. After being associated with the Left and romanticised as natural revolutionaries in the 1950s and 1960s (Crow, 2007), the Mapuche faced harsh treatment under the military dictatorship between 1973 and 1990, and played an important role in the resistance to it (Sznajder, 1998). There is now a strong official recognition of the Mapuche identity and the important role that Mapuche people have played in Chile's history. This recognition is reflected in the usual places in which one might find official symbols of nationhood, such as the national currency. Another illustration is the fact that one the most successful football teams in Chile is named after Colo-Colo, a Mapuche chief who led the resistance against the Spanish in the 16th century. 


\section{INDIGENOUS RIGHTS IN CHILE \\ -10 -}

Yet, the brave warrior image of the Mapuche forms part of a more ambivalent stereotype, which also represents them as lazy, and as alcoholics (Saiz, 2002).

Furthermore, the Mapuche still experience poverty and discrimination, for example in the education and health services (Merino et al., 2009). Some tension between the Mapuche and non-indigenous Chileans has arisen from encroachments by logging companies on land that the Mapuche see as belonging to them. The possible forms of opposition to this may have been constrained by a lack of Mapuche leadership and political representation, and has involved attacks on the crops and machinery of such companies. A recent controversy has surrounded the use of anti-terrorism legislation against Mapuche activists who have damaged property, which human rights organisations have characterised as discriminatory and a "violation of basic due process" (Amnesty International, 2008, p. 93). Therefore the Mapuche are highly regarded in one sense, but discriminated against in another. This makes the Chilean context well suited to exploring the notion of iconic versus egalitarian inclusion.

\section{Study 1}

In April 2008, President Michelle Bachelet announced a new package of multicultural policies to be implemented in Chile. Entitled "Recognition: A Social Pact for Multiculturalism”, this included policies addressing the areas of political rights and cultural diversity, among others. ${ }^{2}$ We sought to opportunistically incorporate these proposals into the study by using them as concrete examples of government policies that participants could give an opinion about. As Verkuyten (2006) points out: "most conflicts in multicultural societies are about specific policies 


\section{INDIGENOUS RIGHTS IN CHILE}

-11 -

and practices" (p. 177). People who endorse minority rights in principle may still object to policies that seek to actually establish these rights in practice. We judged that measuring participants' attitudes about specific policies that had been proposed by the President, rather than abstract principles, would be important for this reason.

We had two main objectives: Firstly, we sought to measure individual differences in iconic and egalitarian inclusion and to confirm our conceptualisation of these as related but distinct constructs. Secondly, we examined the relations between national identification, each type of inclusion and support for policies affecting indigenous people. We expected that individuals who include Mapuche people more within the national definition, both in egalitarian and iconic ways, would be more supportive of the package of multicultural policies.

\section{Method}

\section{Participants}

Participants were recruited from a student population at a large public university in Santiago, Chile. All considered themselves to belong to the Chilean nonindigenous ethnic group. Removing 5 cases with missing data left a sample of 338 for the analysis. One-hundred-and-eighty-five were female and 153. The mean age of the participants was 20.9 years (s.d. $=2.6)$.

Political opinion in the student population is associated with particular areas of study, such that, for example, engineering students are more typically allied to the political right, while humanities and social science students are more typically supportive of the left. We therefore sought to balance the practical advantage of sampling from a student population with the desirability of including participants with a broad range of political opinion by sampling from multiple departments within the 


\section{INDIGENOUS RIGHTS IN CHILE}

-12 -

university. Attempting to include this breadth of opinion is not, of course, the same as seeking a sample that is representative of the Chilean population. The population that was sampled from can be expected to be substantially younger, more urban, wealthier and (unlike the students in some countries) more right wing than the general population of Chile.

\section{Questionnaire}

The questionnaire included measures of national identification, iconic and egalitarian inclusion, support for multicultural policies, and political affiliation (see appendix). These measures are described below.

National identification was measured using 10-items rated on a 7-point agreement scale $(\alpha=.87)$. These items build on a scale previously used by Pehrson $e t$ al. (2009) and are reported in the appendix.

Iconic and egalitarian inclusion were measured using new measures that were developed for the study (see appendix). These were rated by participants on a 7-point scale of agreement or disagreement. The construction of scales from the inclusion and policy measures was based on confirmatory factor analysis, which is reported in the results section below.

Support for multicultural policies was measured using two subscales based on specific policy proposals that were taken from the government's Recognition document (see appendix). Three of these policies related to political representation and three to cultural recognition. Participants indicated how much they agreed with each of these six policies on a 7-point scale.

Social distance was measured by asking participants to indicate on a 7-point scale (from $1=$ 'not at all' to $7=$ 'a lot') how much they would mind having a 


\section{INDIGENOUS RIGHTS IN CHILE \\ -13 -}

Mapuche person as their room-mate, their brother- or sister-in-law, a colleague in a course, their neighbour, their spouse, their doctor, their teacher, and as the President of Chile. The mean score across the 8 items was taken as a reliable single index of social distance $(\alpha=.89)$.

Finally, participants indicated their political affiliation by selecting one of seven options: right, centre right, centre, centre left, left, independent or none. The questionnaire was administered during class time, and participation was on a voluntary basis. After completing the questionnaire, the purpose of the study was explained to the participants.

\section{Results}

\section{Confirmatory factor analysis}

Confirmatory factor analysis was carried out using EQS 6.1 (figure 1). This was necessary to confirm the predicted distinction between iconic and egalitarian inclusion and to examine the relationships between iconic inclusion and different types of multicultural policies. It involved first estimating a simple model with two factors predicting inclusion and policy indicators respectively. The fit indices of model 1 did not quite attain the values that are conventionally regarded as constituting good fit $(\mathrm{CFI}=.85 ;$ RMSEA $=.102)$. The chi-square statistic was 393.31 (d.f. $=89, \mathrm{p}$ $<.001)$. This was then compared to model 2 , in which the inclusion items were assumed to indicate two related factors corresponding to iconic and egalitarian inclusion, rather than one single factor. Model 2 did reach conventional levels of good fit $(\mathrm{CFI}=.93, \mathrm{RMSEA}=.070)$. The chi-square statistic was 229.07 (d.f. $=87, \mathrm{p}<$ .001). The chi-square difference indicates a significant improvement in comparison to model $1\left(\chi^{2}=164.24\right.$, d.f. $\left.=2, p<.001\right)$. A third model was estimated, which retained 


\section{INDIGENOUS RIGHTS IN CHILE}

-14 -

the separate factors for iconic and egalitarian inclusion but also distinguished between the two types of policy, thus including four factors in total. However, a perfect correlation $(\mathrm{r}=1.0)$ between the two policy factors meant that it made no sense to pursue the model. Model 2 therefore constitutes the more appropriate conceptualisation of the variables. The correlations between factors in model 2 indicate that iconic inclusion is positively related to both egalitarian inclusion and multicultural policy.

\section{Regression analysis of national identification, inclusion and policy support}

Scales for national identification, iconic inclusion $(\alpha=.82)$, egalitarian inclusion $(\alpha=.66)$ and policy support $(\alpha=.85)$ were computed based on the factor structure revealed in the previous section, such that policy support is a single construct indicated by both types of policies. The means, standard deviations and inter-correlations for these scales are shown in table I. It is worth noting the very high mean score on the egalitarian inclusion scale. In fact, 79 percent of the sample averaged six or above on this seven-point scale, resulting in a somewhat compressed variance $($ s.d. $=.88$, compared to $>1$ on other measures). This distribution showed a negative skew, which was addressed by computing the inverse of the reversed scores to create a transformed variable for use in the analysis. ${ }^{3}$

Social distance was included as a control variable to reduce any spurious effects arising from both inclusion and policy measures capturing common variance simply reflecting a personal dislike of Mapuche people. At the same time, it also helped to rule out the possibility that a socially desirable response style accounted for the observed relationships, because participants' willingness to appear non-prejudiced

\footnotetext{
${ }^{3}$ This transformation did not in fact affect the results.
} 


\section{INDIGENOUS RIGHTS IN CHILE}

-15 -

should be tapped (and therefore partialed out) by the social distance measure. It was also necessary to control for political affiliations in the analysis, because these could be expected to affect both policy support and inclusion. Political orientation was therefore transformed into a set of six dummy variables to be included in the analysis. The 'none' category served as a baseline, such that the dummy variables compared this category with right, centre right, centre, centre left, left and independent affiliations.

A series of regression models predicting policy support were then estimated. The first step controlled for sex, political orientations and social distance. National identification was added in the second step, with both types of inclusion added in the third. Three product terms representing interactions between each type of inclusion and identification, as well as with each other, were entered in the fourth step. These product terms were computed after centering the predictor scores. The estimates obtained from this model are shown in table II.

The first step indicates that sex, political affiliation and social distance together account for 21 percent of the variance in policy support. People affiliated to the right were significantly less supportive of the policies than those with no affiliation, while those reporting affiliation to the 'centre left' were significantly more supportive. People reporting centre right, centre, left and independent affiliations did not differ significantly from those reporting no affiliation. Social distance was unsurprisingly a negative predictor of policy support.

The second step indicates that national identification was positively associated with policy support. The third step indicates that iconic and egalitarian inclusion both positively predict policy support, independently of one another and of national identification, accounting for an additional 16 percent of the variance in policy 


\section{INDIGENOUS RIGHTS IN CHILE}

-16 -

support. It also shows that the relationship between national identification and policy support does not appear when iconic and egalitarian inclusion are controlled for.

Finally, the fourth step indicates that the relationship between identification and policy support is not moderated by egalitarian or iconic inclusion. There is also no interaction between the two types of inclusion.

\section{Discussion}

Study 1 indicates that two dimensions of national definitions that are inclusive of the Mapuche people can be distinguished. On the one hand, iconic inclusion involves a representation of the Mapuche as an important part of Chilean-ness, historically and symbolically. In contrast, egalitarian inclusion involves representing the Mapuche as citizens of equal importance to the non-indigenous majority. Both iconic and egalitarian inclusion positively predict support for policies that promote indigenous culture and increase indigenous groups' political voice and participation in decision-making.

\section{Study 2}

Study 2 was carried out 20 months after study 1, with data collected between December 2009 and January 2010. The period between studies 1 and 2 was characterised by increasing unrest over the issue of Mapuche claims to ancestral land rights, particularly during the summer and autumn of 2009. Urban riots in Santiago followed the death of a Mapuche individual who was shot by the police whilst occupying a farm as part of a protest over the ancestral land issue.

Whereas support for the Recognition package of multicultural policies might be seen as relatively costless, the more recent unrest surrounding Mapuche direct 


\section{INDIGENOUS RIGHTS IN CHILE}

-17 -

action for land rights and the police response to it is contentious and potentially threatening for our Santiago student samples. In the context of this changing climate around relations between Mapuche people and non-indigenous Chileans, we conducted another survey to assess to role of iconic and egalitarian inclusion in determining reactions to the developments. Study 2 also allowed us to measure additional control variables that have previously been identified as important in intergroup relations, such as right-wing authoritarianism (RWA; Altemeyer, 1988), social dominance orientation (SDO; Sidanius \& Pratto, 1999), and blind and constructive patriotism (Schatz, Staub \& Levine, 1999). This meant that we could therefore clarify the relations between these and the inclusion measures, as well as test the unique contribution of iconic and egalitarian inclusion.

\section{Participants}

Participants were recruited from a student population at higher education institutions in Santiago, Chile. Excluding the responses of 15 participants who did not complete all of the measures left 277 for the analysis. All considered themselves to belong to the Chilean non-indigenous ethnic group. One-hundred-and-seventy-one were female and 106 were male. The mean age of the participants was 22.7 years (s.d. $=3.5)$.

\section{Questionnaire}

The questionnaire included the same measures of national identification $(\alpha=$ $.84)$, iconic inclusion $(\alpha=.81)$, egalitarian inclusion $(\alpha=.88)$, social distance $(\alpha=$ .92) and political affiliation as used in study 1 . In addition, we measured SDO, RWA, blind patriotism and constructive patriotism. These measures are described below. 


\section{INDIGENOUS RIGHTS IN CHILE}

-18 -

Established scales for SDO (10 items; $\alpha=.82)$, RWA (7 items; $\alpha=.71)$, blind patriotism (11 items; $\alpha=.74$ ) and constructive patriotism (6 items; $\alpha=.75$ ) were included in Spanish.

A set of 6 items (see appendix) were constructed to tap attitudes about recent unrest over the land issue, focusing on Mapuche activism and the police reaction to it. High scores indicate a more pro-Mapuche position on this issue. These formed a reliable scale $(\alpha=.72)$.

\section{Results}

\section{Confirmation of factor structure}

We sought to confirm the factor structure established in study 1 , which specifies iconic and egalitarian inclusion as discrete constructs. Thus, two factor models were estimated using EQS 6.1 (see figure 2). Model 1 specified inclusion as a single factor, as well as the two dependent variables: policy support and attitude about the unrest as separate factors. This model did not attain the values conventionally regarded to constitute good fit $(\mathrm{CFI}=.81 ; \mathrm{RMSEA}=.09)$. The chi-square statistic was $654.99($ d.f. $=186)$. Model 2 specified egalitarian and iconic inclusion as separate factors, but was otherwise the same as model 1 . This achieved better fit (CFI $=.90$; RMSEA $=.07)$. The chi-square statistic was $420.16($ d.f. $=184)$, which is a significant improvement in comparison to model $1\left(\chi^{2}=234.83\right.$, d.f. $\left.=2, p<.001\right)$. Model 2 therefore constitutes the more appropriate conceptualisation of the variables.

\section{Inclusion variables and related constructs}

The means, standard deviations and inter-correlations for all scales are shown in table III. Examining the magnitude of the correlations between iconic and 


\section{INDIGENOUS RIGHTS IN CHILE \\ - 19 -}

egalitarian inclusion and SDO, RWA, blind patriotism and constructive patriotism, we see that egalitarian inclusion correlates moderately with SDO but weakly with the other variables. Iconic inclusion correlates weakly with all of the other variables. The strength of these relationship suggests that they are related to other constructs, but they are by no means identical to them.

Futhermore, iconic and egalitarian inclusion differ in their correlations with other important variables. Egalitarian inclusion correlates moderately with SDO, and has a weak to moderate relationship with RWA, while iconic inclusion correlates very weakly with SDO and not at all with RWA. Thus, the two forms of inclusion differ in their patterns of relations with these established constructs.

Regression analysis of national identification, inclusion and policy support

As in study 1, a series of regression models were estimated predicting multicultural policy support (table IV). In the first step, policy support was regressed on the control variables: sex, political affiliation, RWA, SDO, blind and constructive patriotism, and social distance. ${ }^{4}$ This control model accounted for 35 percent of the variance in policy support.

In the second step, national identification was added to the model. This model did not significantly increase the variance explained. Furthermore, in contrast to study 1, national identification was not a predictor of policy support.

Lastly, in the third step, egalitarian and iconic inclusion were added to the model. The addition of these variables accounted for a further 25 percent of the

\footnotetext{
${ }^{4}$ SDO scores were positively skewed. This was corrected by calculating the natural logarithm to create a normally distributed variable, which was then used for the regression analysis.
} 


\section{INDIGENOUS RIGHTS IN CHILE}

-20 -

variance. Again both egalitarian and iconic inclusion positively predicted policy support, although the beta weight for iconic inclusion was small, indicating a weaker relationship than that observed in study $1 .^{5}$

The same models were then estimated with attitude about the unrest over the land issue as the dependent variable (table IV). In step one, the control variables account for 34 percent of the variance. Again, the addition of national identification in step 2 does not significantly increase the variance explained. Finally, in step 3, the addition of iconic and egalitarian inclusion explains an additional 7 percent of the variance in attitudes about the unrest. While iconic inclusion is predictive of a more pro-Mapuche position on this issue, egalitarian inclusion appears to be unrelated. Furthermore, with the addition of the inclusion variables to the model, the beta weight for national identification is strengthened and becomes significantly negative.

\section{Discussion}

Study 2 confirms the 2 -factor structure of the inclusion variables, and further clarifies their relationship with established constructs known to be related to political attitudes: SDO, RWA, blind patriotism and constructive patriotism. The moderate correlation between egalitarian inclusion and SDO is unsurprising given that both constructs relate to some sense of equality versus inequality between groups. However, at .45 , the correlation is not so high that we need conclude that the constructs are identical. Indeed, SDO correlates more strongly with RWA than it does

5 As in study 1, the 2-way interaction terms between national identification, iconic inclusion and egalitarian inclusion were tested. Again, this did not indicate any interaction effects. 


\section{INDIGENOUS RIGHTS IN CHILE}

-21 -

with egalitarian inclusion. Egalitarian inclusion also shows an independent relationship with support for multicultural policy in the final model while SDO does not, which suggests against the former being redundant.

Study 2 also broadly replicates the finding that both forms of inclusion independently predict support for the multicultural policies, although the path for iconic inclusion is rather weak, while the path for egalitarian inclusion is stronger. This most probably reflects the fact that egalitarian inclusion scores are slightly lower with more variance in study 2 , a likely consequence of the more strained relations between the Mapuche and non-indigenous Chileans at the time of study 2. It is also noteworthy that the addition of the inclusion variables to the model in step 3 accounts for a further 25 percent of the variance in support for multicultural policies, increasing the total variance explained to over 60 percent. This level of improvement to a model that already includes political affiliations, RWA, SDO, national identification, blind and constructive patriotism and social distance is considerable and speaks to the unique importance of national definitions to people's support for indigenous rights.

In addition, study 2 extends the findings of study 1 by examining attitudes about the unrest surrounding the issue of ancestral land claims. In this case, we again found evidence that inclusive national definitions matter, although it was iconic inclusion rather than egalitarian inclusion that was predictive of a pro-Mapuche position. This is interesting for a number of reasons: First, it demonstrates that iconic and egalitarian inclusion are respectively more predictive of different outcomes, which speaks to the validity of the distinction between them. Second, it suggests that we cannot view symbolic inclusion simply as an easy expression of inclusion that counts for little when more costly forms of resource allocation are at stake (cf. Liu \& Sibley, 2006). On the contrary, it was precisely with the more controversial issue of 


\section{INDIGENOUS RIGHTS IN CHILE}

-22 -

more radical activism by Mapuche people over the issue of land rights that we saw the predictive importance of iconic inclusion. Thus, it appears that iconic inclusion actually goes further than egalitarian inclusion does in terms of assigning the Mapuche an essential position, as a group, in the country's formation.

\section{General Discussion}

The results are consistent with our view that the way in which non-indigenous people define their national group, including or excluding indigenous minorities, is consequential for their level of support for indigenous rights. In contexts involving immigrants, researchers have drawn on the distinction between ethnic and civic nationalisms in order to examine relations between national definitions and reactions to immigration, whereby ethnic definitions are understood as relatively exclusive while civic definitions as relatively inclusive (e.g. Pehrson \& Green, in press). We have extended this to examine support for indigenous rights in Chile, proposing a distinction between two different forms of inclusion: iconic and egalitarian. We found that these form discrete but positively related constructs with independent predictive relations with support for indigenous rights.

Discourse analytic work has pointed to a more complex relation between inclusion of indigenous groups in the national definition and support for indigenous rights. For example, in New Zealand, it has been noted that a so-called 'culture as heritage' discourse, which closely parallels what we call iconic inclusion, can function to de-legitimize the political action of indigenous groups, even as it ostensibly holds those groups in high esteem as a valuable part of the nation: Members of a majority group may appropriate the culture of a minority, or some 


\section{INDIGENOUS RIGHTS IN CHILE \\ -23 -}

version of it, whilst maintaining their own domination in the political sphere (Wetherell \& Potter, 1992).

Yet, our findings are inconsistent with the view that iconic inclusion (in this context) actually constitutes a form of domination, whereby the majority appropriates indigenous symbols whilst seeking to keep indigenous people politically oppressed, and it seems to reflect a more genuine 'politics of recognition' (Taylor, 1992). What may be crucial in determining the difference between an iconic inclusion that is supportive of movements for indigenous rights and an appropriative stance that undermines them is the degree to which the representation forces indigenous people to play a passive, de-politicised role in order not to be spurned as inauthentic. Chilean representations of the Mapuche might in fact be rather unusual in that, as we have described, historical themes of resistance are central to them. Thus, more radical activism might be seen by non-indigenous people as an authentic expression of Mapuche identity in a way that is not possible for indigenous people in other countries, such as New Zealand, where resistance is construed as a betrayal of 'traditional' indigenous culture or a lack of rootedness in it (Wetherell \& Potter, 1992). In extending these findings to other contexts involving indigenous minorities, then, it will be necessary for future research to examine not only inclusion versus exclusion, but also the degree to which indigenous identity is represented in such a way that political activism is construed either as expressive or subversive of it.

More generally, while we see the content of national identities as being important in determining support for indigenous rights not only in Chile, but elsewhere as well, it does not necessarily follow that the two dimensions of inclusion themselves and their consequences are universal. Our approach has been to incorporate measures of specific identity content into the analysis, rather than attempt 


\section{INDIGENOUS RIGHTS IN CHILE}

-24 -

to develop new general dimensions of national identity. Attention to local and specific identity content will always be needed.

Lastly, while iconic inclusion, for the non-indigenous participants, is associated with support for indigenous rights, and therefore does not seem to be characterised by appropriation, Mapuche and other indigenous people might see things differently. In other words, what is recognition to the majority may be seen as appropriation by the minority. The only way to confirm whether or not this is the case would be to carry out studies that include the perspectives of Mapuche people, which the current study unfortunately did not. However, such a possibility would be consistent with anthropological work that has focused on conflicts over the ownership of certain identities and symbols associated with them. Harrison (2002), for example, argues that markers of social identities can operate as a form of property which can be the focus of struggles between groups.

These points, and the current findings, add further weight to the argument that representations of the ingroup, and not only of the outgroup, play an important a role in intergroup relations (Reicher, Hopkins, Levine, \& Rath, 2005). They also feed into recent theoretical work within the social identity tradition on political solidarity, whereby minority rights mobilizations involve a contest over the meaning of a shared category with the majority (Subašić et al., 2008). From this perspective, social change is seen to result from majority group solidarity with the minority against an authority with which the minority is in conflict. Such solidarity is possible when members of the majority see their identity as being shared with the minority rather than with the authority, such that supporting minority demands becomes a way of realising the norms associated with the relevant self-category (e.g. Chilean). In line with this, the 
INDIGENOUS RIGHTS IN CHILE

-25 -

current findings demonstrate the relevance of particular meanings and definitions of national groups to majority group members' solidarity with an indigenous minority.

Precisely because they shape the possibilities for solidarity and are therefore a source of power, representations of the national ingroup do not reside passively and organically within the group. Rather, they are constructed through ongoing political struggles and mobilizations (for a similar argument regarding national definitions and citizenship regimes, see Joppke \& Rosenhek, 2002). Social identity, therefore, need not be seen as some kind of autonomous influence on political processes, but rather as a medium through which a variety of interests are pursued. Consequently, the social identity perspective has a great deal to contribute to the understanding of political processes. In order for this to be realised, however, the approach needs to incorporate an appreciation for the particular meanings and definitions of the social categories involved in a given context. 


\section{INDIGENOUS RIGHTS IN CHILE}

$-26-$

\section{REFERENCES}

Altemeyer, B. (1988). Enemies of freedom: Understanding right-wing authoritarianism. San Fransisco: Jossey-Blass.

Amnesty International (2008). Report 2008: State of the world's human rights. Retrieved May 2008 from http://thereport.amnesty.org/.

Augoustinos, M., Tuffin, K., \& Rapley, M. (1999). Genocide or a failure to gel? Racism, history and nationalism in Australian talk. Discourse \& Society, 10, $351-378$.

Billig, M. (1995). Banal nationalism. London: Thousand Oaks.

Brown, R., González, R., Zagefka, H., Manzi, J., \& Čehajić, S. (2008). Nuestra culpa: Collective guilt and shame as predictors of reparation for historical wrongdoing. Journal of Personality and Social Psychology, 94(1), 75-90.

Cameron, J. E., \& Lalonde, R. N. (2001). Social identification and gender-related ideology in women and men. British Journal of Social Psychology, 40, 59-77.

Crow, J. (2007). Debates about ethnicity, class and nation in Allende's Chile. Bulletin of Latin American Research, 26(3), 319-338.

Drury, J., \& Reicher, S. (2005). Explaining enduring empowerment: A comparative study of collective action and psychological outcomes. European Journal of Social Psychology, 35, 35-58.

Gacitúa-Marió, E. (2000). Indigenous peoples in Chile: Current situation and policy issues: World Bank. 


\section{INDIGENOUS RIGHTS IN CHILE}

-27 -

González, R., Manzi, J., Saiz, H., Brewer, M., Tezanos-Pinto, Torres, D., et al. (2008). Interparty attitudes in Chile: Coalitions as Superordinate Social Identities. Political Psychology, 29(1), 93-118.

Harrison, S. (2002). The politics of resemblance: Ethnicity, trademarks, head-hunting. Journal of the Royal Anthropological Institute, 8, 211-232.

Haslam, S. A., \& Platow, M. J. (2001). The link between leadership and followership: how affirming social identity translates vision into action. Personality and Social Psychology Bulletin, 27(11), 1469-1479.

Hogg, M. A., \& Smith, J. R. (2007). Attitudes in social context: A social identity perspective. European Review of Social Psychology, 18, 89-131.

Huddy, L. (2001). From social to political identity: A critical examination of social identity theory. Political Psychology, 22(1), 127-156.

Joppke, C., \& Rosenhek, Z. (2002). Contesting ethnic immigration: Germany and Israel compared. European Journal of Sociology, 43, 301-335.

Kundnani, A. (2007). The end of tolerance: Racism in 21st century Britain. London: Pluto Press.

Kymlicka, W. (2001). Politics in the vernacular: Nationalism, multiculturalism and citizenship. Oxford: Oxford University Press.

Kymlicka, W. (2002). Contemporary political philosophy: Oxford University Press.

Liu, J. H., \& Sibley, C. G. (2006). Differential effects of societal anchoring and attitude certainty in determining support or opposition to (bi) cultural diversity in New Zealand. Papers on Social Representations, 15, 1.1-1.15.

Livingstone, A., \& Haslam, S. A. (2008). The importance of social identity content in a setting of chronic social conflict: Understanding intergroup relations in Northern Ireland. British Journal of Social Psychology, 47(1), 1-21. 


\section{INDIGENOUS RIGHTS IN CHILE}

-28 -

Merino, M.-E., Mellor, D. J., Saiz, J. L., \& Quilaqueo, D. (2009). Perceived discrimination amongst the indigenous Mapuche people in Chile: some comparisons with Australia. Ethnic and Racial Studies, 32, 802-822.

Pehrson, S., Brown, R., \& Zagefka, H. (2009). When does national identification lead to anti-immigrant prejudice? Cross-sectional and longitudinal evidence to the role of essentialist ingroup definitions. British Journal of Social Psychology, $48,61-76$.

Pehrson, S. \& Green, E. G. T. (in press). Who we are and who can join us: National identity content and entry criteria for new immigrants. Journal of Social Issues.

Pehrson, S., Vignoles, V. L., \& Brown, R. (2009). National identification and antiimmigrant prejudice: individual and contextual effects of national definitions. Social Psychology Quarterly, 72(1), 24-38.

Polletta, F. \& Jasper, J. M. (2001). Collective identity and social movements. Annual Review of Sociology, 27, 283-305.

Pratto, F., Sidanius, J., \& Levin, S. (2006). Social dominance theory and the dynamics of intergroup relations: Taking stock and looking forward. European Journal of Social Psychology, 17, 279-321.

Reicher, S. (2004). The context of social identity: Domination, resistance and change. Political Psychology, 25(6), 921-945.

Reicher, S., \& Hopkins, N. (2001a). Psychology and the end of history: A critique and a proposal for the psychology of social categorization. Political Psychology, 22(2), 383-407.

Reicher, S., \& Hopkins, N. (2001b). Self and nation. London: Sage. 


\section{INDIGENOUS RIGHTS IN CHILE \\ - 29 -}

Reicher, S., Hopkins, N., Levine, M., \& Rath, R. (2005). Entrepreneurs of hate and entrepreneurs of solidarity: Social identity as a basis for mass communication. International Review of the Red Cross, 87(860), 621-637.

Saiz, J.-L. (2002). Atributión de estereotipos: Los indígenas mapuches que perciben los chilenos. In J. F. Morales, D. Páez, A. L. Kornblit \& D. Asún (Eds.), Psicología social. Buenos Aires: Prentice-Hall-Pearson Education.

Schatz, R. T., Staub, E., \& Lavine, H. (1999). On the varieties of national attachment: Blind versus constructive patriotism. Political Psychology, 20, 151-174.

Simon, B., \& Klandermans, B. (2001). Politicized collective identity: A social psychological analysis. American Psychologist, 56(4), 319-331.

Subašić, E., Reynolds, K. J., \& Turner, J. C. (2008). The political solidarity model of social change: Dynamics of self-categorization in intergroup power relations. Personality and Social Psychology Review, 12, 330-352.

Sznajder, M. (1998). Who is Chilean? The Mapuche, the huaso and the roto as the basic symbols of chilean collective identity. In L. Roniger \& M. Sznajer (Eds.), Constructing collective identities and shaping public spheres: Sussex Academic Press.

Tajfel, H. (1972). Experiments in a vacuum. In J. Israel \& H. Tajfel (Eds.), The context of social psychology: A critical assessment. London: Academic Press.

Tajfel, H. (1978a). Social categorization, social identity and social comparison. In H. Tajfel (Ed.), Differentiation between social groups: Studies in the social psychology of intergroup relations (pp. 61-76). London: Academic Press.

Tajfel, H. (1978b). The social psychology of minorities. London: Minority Rights Group. 


\section{INDIGENOUS RIGHTS IN CHILE}

- 30 -

Tajfel, H. (1981). Human groups and social categories: Studies in social psychology. Cambridge: Cambridge University Press.

Tajfel, H., \& Turner, J. C. (1979). An integrative theory of intergroup conflict. In W. Austin \& S. Worchel (Eds.), The psychology of intergroup relations (pp. 3347). Monterey, CA: Brookes Cole.

Taylor, C. (1992). The Politics of Recognition. In A. Gutmann (Ed.), Multiculturalism and 'the politics of recognition' (pp. 25-73). Princeton: Princeton University Press.

Turner, J., Hogg, M., Oakes, P., Reicher, S., \& Wetherell, M. (1987). Rediscovering the social group: A self-categorization theory. Oxford, UK: Blackwell.

Turner, J. C. (1999). Some current issues in research on social identity and selfcategorization theories. In N. Ellemers, R. Spears \& B. Doosje (Eds.), Social identity: Context, commitment, content. Oxford: Blackwell.

van Zomeren, M., Postmes, T., \& Spears, R. (2008). Toward an integrative social identity model of collective action: A quantitative research synthesis of three socio-psychological perspectives. Psychological Bulletin, 134, 504-535.

Verkuyten, M. (2006). Multicultural recognition and ethnic minority rights: A social identity perspective. European Review of Social Psychology, 17, 148-184.

Wenzel, M., Mummendey, A., \& Waldzus, S. (2007). Superordinate identities and intergroup conflict: The ingroup projection model. European Review of Social Psychology, 18, 331-372.

Wetherell, M. and Potter, J. (1992) Mapping the language of racism: Discourse and the legitimation of exploitation. Hemel Hempstead: Harvester Wheatsheaf. 


\section{INDIGENOUS RIGHTS IN CHILE}

-31 -

Wohl, M. J. A., Branscombe, N. R., \& Klar, Y. (2006). Collective guilt: Emotional reactions when one's group has done wrong or been wronged. European Review of Social Psychology, 17, 1-37. 


\section{INDIGENOUS RIGHTS IN CHILE}

- 32 -

Figure 1: Path diagrams show CFA models for inclusion and policy support indicators in study 1

(a) Model 1

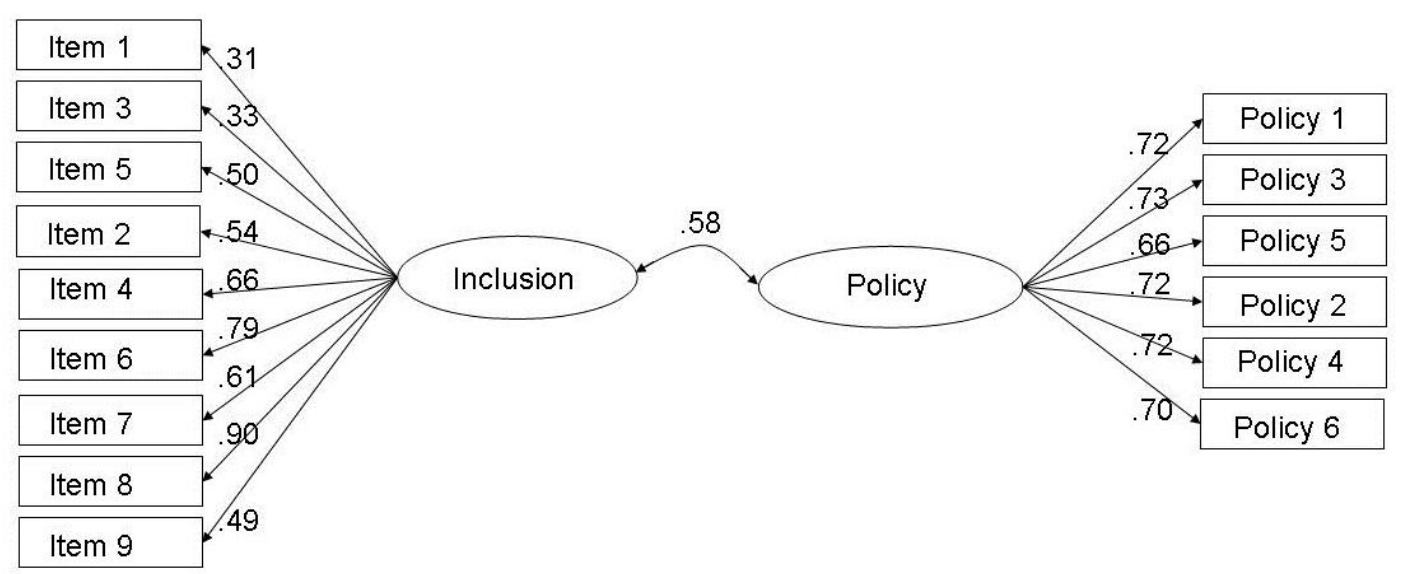

(b) Model 2

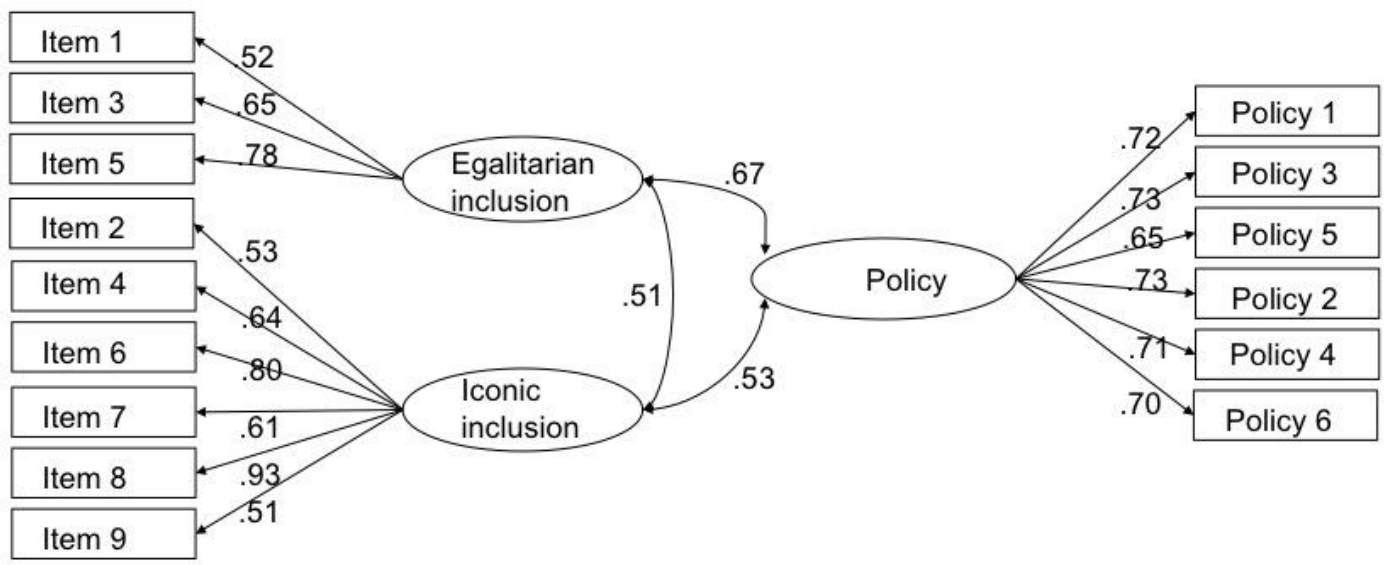


Figure 2: Path diagrams show CFA models for inclusion, policy support, and attitudes about unrest over the ancestral land rights issue in study 2

(a) Model 1

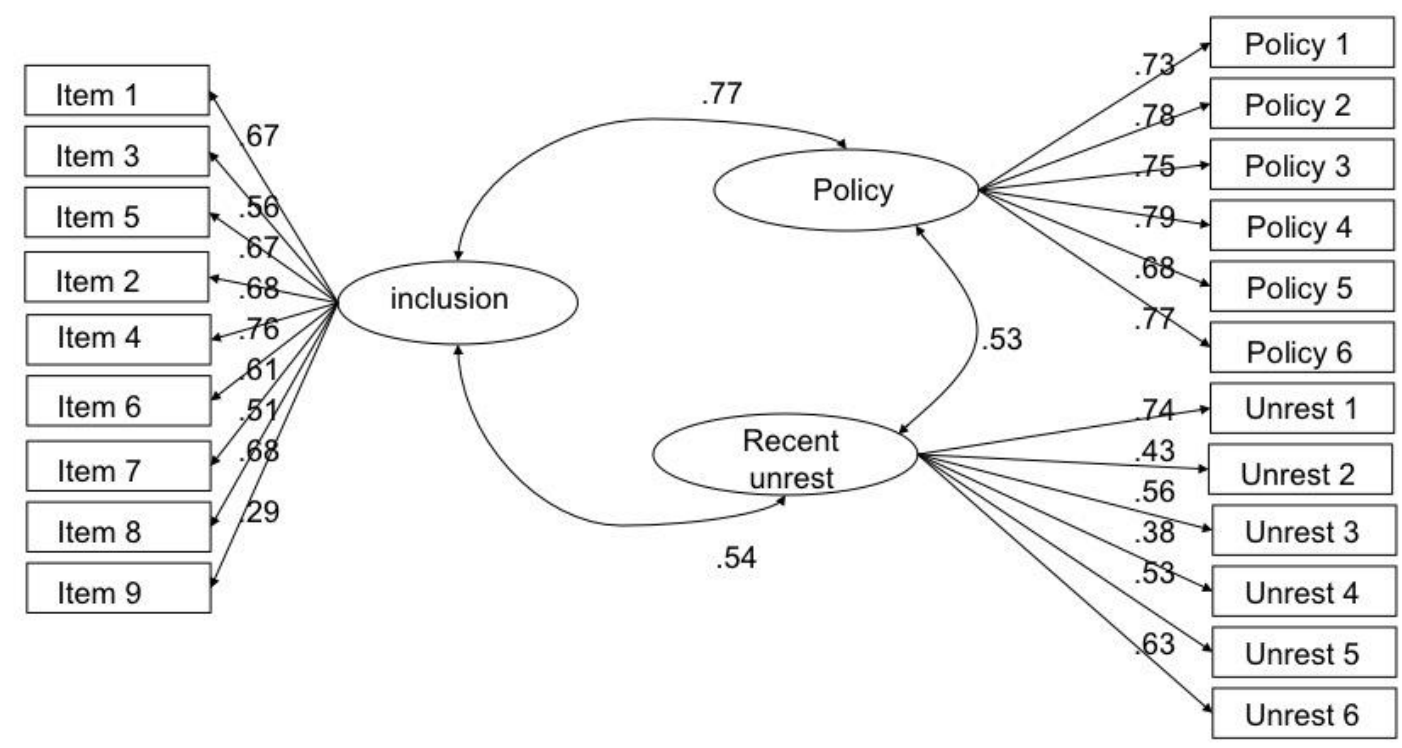

(b) Model 2

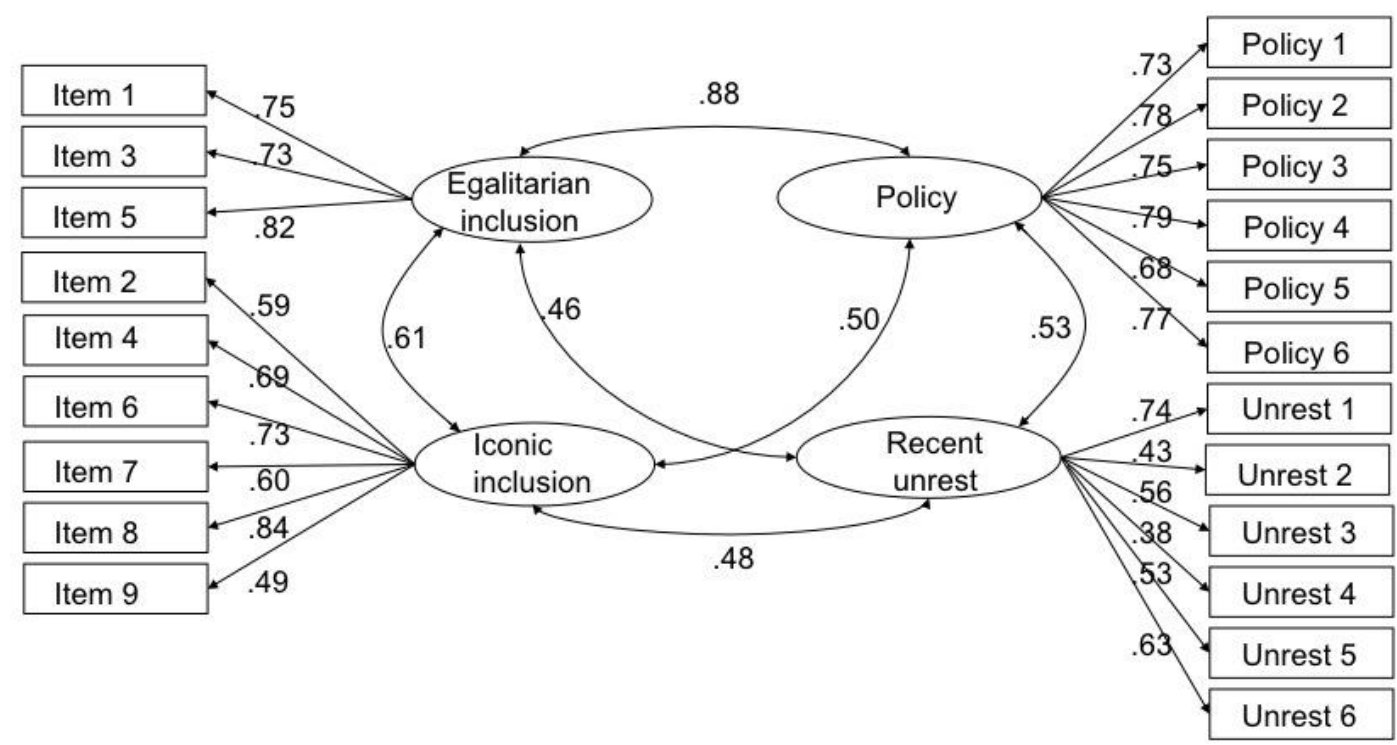




\section{INDIGENOUS RIGHTS IN CHILE}

\section{- 34 -}

Table I: Means, standard deviations and inter-correlations for national identification, iconic and egalitarian inclusion and multicultural policy support

\begin{tabular}{l|l:lll}
\hline & Mean (s.d.) & $\mathbf{2 .}$ & $\mathbf{3 .}$ & $\mathbf{4 .}$ \\
1. National identification & $5.28(1.09)$ & .30 & .25 & .19 \\
2. Iconic inclusion & $4.71(1.19)$ & - & .39 & .46 \\
3. Egalitarian inclusion & $6.38(.88)$ & - & - & .52 \\
4. Multicultural policy support & $5.77(1.07)$ & - & - & - \\
\hline
\end{tabular}

Note: all correlations are statistically significant at $\mathrm{p}<.01$ 
Table II: Regression of multicultural policy support on political affiliation, national identification and iconic and egalitarian inclusion.

\section{Step $1 \quad$ Step $2 \quad$ Step $3 \quad$ Step 4}

\section{STANDARDISED BETAS}

Sex $(1=$ =male; $2=$ female $)$

$\begin{array}{llll}.15^{* *} & .13^{*} & .04 & .05\end{array}$

\section{Political Affiliation}

Right

Centre Right

$-.17^{* *} \quad-.22^{* *} \quad-.14^{*} \quad-.13^{*}$

Centre

$\begin{array}{llll}-.04 & -.06 & -.03 & -.03\end{array}$

Centre left

$\begin{array}{llll}-.06 & -.07 & -.07 & -.06\end{array}$

Left

$\begin{array}{llll}.11^{*} & .09^{\dagger} & .04 & .05\end{array}$

Independent

$\begin{array}{llll}.04 & .03 & .01 & .01\end{array}$

Social distance

$\begin{array}{llll}.00 & .00 & -.03 & -.03\end{array}$

National identification

$\begin{array}{llll}-.30^{* *} & -.27^{* *} & -.14^{* *} & -.14^{* *}\end{array}$

Iconic inclusion

$\begin{array}{llll}- & .18^{* *} & .04 & .04\end{array}$

Egalitarian inclusion

$.25^{* *} \quad .26^{* *}$

Interactions:

National identification $\mathrm{x}$ iconic inclusion

$\begin{array}{llll}- & - & - & 05\end{array}$

National identification $\mathrm{x}$ egalitarian inclusion

Iconic $\mathrm{x}$ egalitarian inclusion

$-.01$

$\begin{array}{lllll}\mathbf{R}^{2} & .21^{* *} & .24^{* *} & .40^{* *} & .41^{* *} \\ \mathbf{R}^{2} \text { CHANGE } & - & .03^{* *} & .16^{* *} & .01\end{array}$

Note: ${ }^{\dagger} \mathrm{p} \leq .10 ;{ }^{*} \mathrm{p} \leq .05 ;{ }^{* *} \mathrm{p} \leq .01$ (two-tailed). 


\section{INDIGENOUS RIGHTS IN CHILE}

- 36 -

Table III: Means, standard deviations and inter-correlations for national identification, iconic and egalitarian inclusion and multicultural policy support

\begin{tabular}{|c|c|c|c|c|c|c|c|c|c|c|}
\hline & Mean (s.d.) & 2. & 3. & 4. & 5. & 6. & 7. & 8. & 9. & 10. \\
\hline 1. National identification & $5.38(1.06)$ & $.29^{* *}$ & $.30^{* *}$ & $-.11^{\dagger}$ & $.18^{* *}$ & $.61^{* *}$ & $.39^{* *}$ & -.06 & $.15^{*}$ & -.08 \\
\hline 2. Iconic inclusion & $4.76(1.25)$ & - & $.47^{* *}$ & $-.14^{*}$ & .01 & $.22^{* *}$ & $.12^{\dagger}$ & $-.24^{* *}$ & $.40^{* *}$ & $.34^{* *}$ \\
\hline 3. Egalitarian inclusion & $6.19(1.21)$ & - & - & $-.45^{* *}$ & $-.26^{* *}$ & $.23^{* *}$ & -.06 & $-.42^{* *}$ & $.73^{* *}$ & $.35^{* *}$ \\
\hline 4. SDO & $2.30(1.05)$ & - & - & - & $.55^{* *}$ & -.10 & $.31^{* *}$ & $.41^{* *}$ & $-.45^{* *}$ & $-.40^{* *}$ \\
\hline 5. RWA & $3.53(1.14)$ & - & - & - & - & $.20^{* *}$ & $.53^{* *}$ & $.27^{* *}$ & $-.37^{* *}$ & $-.37^{* *}$ \\
\hline 6. Constructive patriotism & $5.29(1.09)$ & - & - & - & - & - & $.30^{* *}$ & -.02 & $.14^{*}$ & .02 \\
\hline 7. Blind patriotism & $3.34(.89)$ & - & - & - & - & - & - & $.20^{* *}$ & $-.16^{* *}$ & $-.23^{* *}$ \\
\hline 8. Social distance & $1.87(1.34)$ & - & - & - & - & - & - & - & $-.45^{* *}$ & $-.31^{* *}$ \\
\hline 9. Multicultural policy support & $5.79(1.19)$ & - & - & - & - & - & - & - & - & $.45^{* *}$ \\
\hline 10. Attitude about recent unrest & $4.49(1.20)$ & - & - & - & - & - & - & - & - & - \\
\hline
\end{tabular}

Note: ${ }^{\dagger} \mathrm{p} \leq .10 ;{ }^{*} \mathrm{p} \leq .05 ;{ }^{* *} \mathrm{p} \leq .01$ (two-tailed). 


\section{INDIGENOUS RIGHTS IN CHILE}

- 37 -

Table IV: Regression of model predicting multicultural policy support and attitude toward Mapuche activism (study 2).

\begin{tabular}{|c|c|c|c|c|c|c|}
\hline & \multicolumn{3}{|c|}{ Multicultural policy } & \multicolumn{3}{|c|}{$\begin{array}{c}\text { Attitude about recent } \\
\text { unrest }\end{array}$} \\
\hline STANDARDISED BETAS & Step 1 & Step 2 & Step 3 & Step 1 & Step 2 & Step 3 \\
\hline Sex $(1=$ male; $2=$ female $)$ & $.12^{*}$ & $.11^{*}$ & .05 & $.10^{\dagger}$ & $.10^{*}$ & .07 \\
\hline \multicolumn{7}{|l|}{ Political Affiliation } \\
\hline Right & -.08 & -.08 & -.04 & $-.17^{* *}$ & $-.15^{* *}$ & $-.11^{*}$ \\
\hline Centre Right & .03 & .02 & .04 & -.09 & -.08 & -.06 \\
\hline Centre & .06 & .06 & $.09^{*}$ & -.03 & -.02 & -.02 \\
\hline Centre left & .03 & .02 & .01 & -.06 & -.05 & -.06 \\
\hline Left & -.01 & -.01 & -.02 & $.28^{* *}$ & $.28^{* * *}$ & $.25^{* *}$ \\
\hline Independent & .03 & .03 & -.00 & $.10^{\dagger}$ & $.10^{\dagger}$ & $.11^{*}$ \\
\hline \multicolumn{7}{|l|}{ Additional control variables } \\
\hline SDO & $-.18^{*}$ & $-.17^{*}$ & -.06 & $-.18^{*}$ & $-.19^{*}$ & $-.17^{*}$ \\
\hline RWA & $-.22^{*}$ & $-.22^{*}$ & $-.16^{* *}$ & -.11 & -.11 & $-.12^{\dagger}$ \\
\hline Blind patriotism & .05 & .02 & .01 & -.01 & .02 & .01 \\
\hline Constructive patriotism & $.15^{* *}$ & .10 & .05 & .06 & $.12^{\dagger}$ & $.10^{\dagger}$ \\
\hline Social distance & $-.32^{* *}$ & $-.31^{* *}$ & $-.13^{*}$ & $-.12^{*}$ & $-.13^{*}$ & -.06 \\
\hline National identification & & .10 & -.07 & & $-.12^{\dagger}$ & $-.19^{* *}$ \\
\hline Iconic inclusion & & & $.09^{*}$ & & & $.25^{* *}$ \\
\hline Egalitarian inclusion & & & $.57^{* *}$ & & & .08 \\
\hline $\mathbf{R}^{2}$ & $.35^{*-1}$ & $.36^{6-1}$ & $.60^{*}$ & $.37^{* *}$ & $.37^{* *}$ & $.44^{* *}$ \\
\hline $\mathbf{R}^{2}$ CHANGE & & .01 & $.25^{* *}$ & & $.01^{\dagger}$ & $.06^{* *}$ \\
\hline
\end{tabular}

Note: ${ }^{\dagger} \mathrm{p} \leq .10 ;{ }^{*} \mathrm{p} \leq .05 ;{ }^{* *} \mathrm{p} \leq .01$ (two-tailed). 


\section{INDIGENOUS RIGHTS IN CHILE}

- 38 -

Appendix: Items for inclusion and policy support. Note: Spanish versions used in the questionnaire are available from the authors.

\section{NATIONAL IDENTIFICATION}

Item 1 I'm glad to be Chilean.

Item 2 I feel committed to Chilean people.

Item 3 I show solidarity with Chilean people.

Item 4 When I talk about Chileans, I usually say 'they' rather than 'we'. (reverse coded)

Item $5 \quad$ Being Chilean gives me a sense of who I am.

Item 6 Being Chilean is not an important part of how I see myself. (reverse coded)

Item $7 \quad$ I have a strong sense of belonging with Chilean people.

Item $8 \quad$ Being Chilean makes me proud.

Item 9 Whatever happens to Chileans as a group affects me personally.

Item 10 Being Chilean is central to my identity

\section{EGALITARIAN INCLUSION}

Item 1 The Mapuche and non-indigenous people should show solidarity with one another.

Item 3 The Mapuche and non-indigenous people in Chile should be equal members of society.

Item 5 The situation of both Mapuche and non-indigenous people is important to the future of our country.

\section{ICONIC INCLUSION}

Item 2 The Mapuche personify many of the real Chilean values.

Item 4 Lautaro, Caupolicán, and other Mapuche figures help to define the Chilean national character.

Item 6 Chilean identity is defined importantly by the Mapuche culture.

Item 7 The indigenous people, such as the Mapuche, are a historically important part of the Chilean nation.

Item $8 \quad$ We owe an important part of the Chilean identity to Mapuche culture.

Item 9 The Chilean way of being is based on the Mapuche way of being. 


\section{INDIGENOUS RIGHTS IN CHILE \\ - 39 -}

\section{POLICY: REPRESENTATION}

Policy 1 A new council of indigenous people for consultation on indigenous policy.

Policy 3 The formalization in law of indigenous people's right to participate in decisions affecting them.

Policy 5 The election of indigenous representatives in both houses of congress

\section{POLICY: CULTURE}

Policy 2 The formal recognition of cultural, social and religious practices of the indigenous people

Policy 4 Programs to encourage indigenous culture, such as special academies for indigenous languages

Policy 6 Investment in programmes of intercultural education in nursery schools with high indigenous presence

\section{ATTITUDE ABOUT RECENT UNREST OVER THE LAND ISSUE}

Unrest 1 The police reaction to Mapuche protests has been too violent.

Unrest 2 The authorities need to get tougher on the Mapuche individuals causing disturbances. (reverse coded)

Unrest 3 Any police officers guilty of using violence against Mapuche protestors should be held to account.

Unrest 4 The Mapuche are too assertive in claiming ancestral lands. (reverse coded)

Unrest 5 The current government has not been fair towards the Mapuche over their claims to ancestral lands.

Unrest 6 I am broadly sympathetic to recent Mapuche activism over the land issue. 